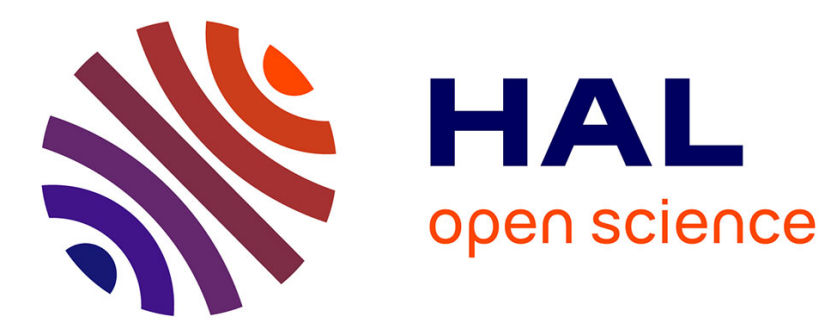

\title{
Inorganic arsenic speciation in the waters of the Penzé estuary (NW France): Seasonal variations and fluxes to the coastal area
}

Jennifer Vandenhecke, Matthieu Waeles, Jean-Yves Cabon, Cédric Garnier, Ricardo D. Riso

\section{To cite this version:}

Jennifer Vandenhecke, Matthieu Waeles, Jean-Yves Cabon, Cédric Garnier, Ricardo D. Riso. Inorganic arsenic speciation in the waters of the Penzé estuary (NW France): Seasonal variations and fluxes to the coastal area. Estuarine, Coastal and Shelf Science, 2010, 90, pp.221-230. 10.1016/j.ecss.2010.09.003 . hal-01096840

\section{HAL Id: hal-01096840 \\ https://hal-univ-tln.archives-ouvertes.fr/hal-01096840}

Submitted on 5 Jan 2015

HAL is a multi-disciplinary open access archive for the deposit and dissemination of scientific research documents, whether they are published or not. The documents may come from teaching and research institutions in France or abroad, or from public or private research centers.
L'archive ouverte pluridisciplinaire HAL, est destinée au dépôt et à la diffusion de documents scientifiques de niveau recherche, publiés ou non, émanant des établissements d'enseignement et de recherche français ou étrangers, des laboratoires publics ou privés. 


\title{
Inorganic arsenic speciation in the waters of the Penzé estuary (NW France): Seasonal variations and fluxes to the coastal area
}

\author{
Jennifer Vandenhecke ${ }^{\mathrm{a}, \mathrm{b}}$, Matthieu Waeles ${ }^{\mathrm{a}, \mathrm{b}, *}$, Jean-Yves Cabon ${ }^{\mathrm{a}, \mathrm{c}}$, Cédric Garnier ${ }^{\mathrm{d}}$, Ricardo D. Riso ${ }^{\mathrm{a}, \mathrm{b}}$ \\ ${ }^{a}$ Université Européenne de Bretagne, Brest, France \\ ${ }^{\mathrm{b}}$ Université de Bretagne Occidentale, IUEM, LEMAR, UMR-CNRS 6539, Equipe Chimie Marine, place N. Copernic, 29280 Plouzané, France \\ ${ }^{c}$ Université de Bretagne Occidentale, UMR-CNRS 6521, 6 avenue V. Le Gorgeu, CS 93837, 29238 Brest Cedex 3, France \\ ${ }^{\mathrm{d}}$ Laboratoire PROTEE, Université du Sud Toulon-Var-BP 20132, 83957 La Garde, France
}

\section{A R T I C L E I N F O}

\section{Article history:}

Received 17 June 2010

Accepted 16 September 2010

Available online 28 September 2010

\section{Keywords:}

arsenic

inorganic species

estuary

seasonal variations

fluxes

\begin{abstract}
A B S T R A C T
Over this one-year study, the variations of inorganic As species were examined monthly along the salinity gradient of the Penzé estuary (NW France) in relation with different biogeochemical parameters. In most cases, dissolved As exhibited a non-conservative behaviour which resulted from the competition between two major processes. In the upstream section of the estuary, a strong input of both total inorganic As and As(III) occurred. Then, the removal of the same species, under precipitation of iron oxides/oxyhydroxides, was observed in the low-salinity range $(S<10)$. Using our experimental data, the fluxes of the various As species were estimated for the first time in estuarine waters. Inputs from the river were mainly constituted of particulate As $(\sim 70 \%)$. Conversely, dissolved species were predominant in the net fluxes $(\sim 65 \%)$ and $\mathrm{As}(\mathrm{III})$ accounted for $\sim 15 \%$ of the dissolved net flux.
\end{abstract}

(c) 2010 Elsevier Ltd. All rights reserved.

\section{Introduction}

Like most trace elements, arsenic is mainly transported to the marine environment by rivers through estuaries. Chilvers and Peterson (1987) and Duce and Liss (1991) estimated the annual world input through the streams as $10-60 \times 10^{4} \mathrm{~T}$ in dissolved form and $80-180 \times 10^{4} \mathrm{~T}$ in particulate form. On the other hand, in the estimation by Matschullat (2000), the contribution of dissolved As was upgraded $\left(60 \times 10^{4} \mathrm{~T} \mathrm{y}^{-1}\right)$ and outmatched the one of particulate As $\left(20 \times 10^{4} \mathrm{~T} \mathrm{y}^{-1}\right)$. However, the uncertainties about arsenic inputs from the rivers are still high, because the pre-cited estimations do not take into account the physico-chemical processes that can affect the distribution of this metalloid in estuaries.

A large number of studies have dealt with arsenic in estuaries. Contrarily to some other elements, the behaviour of dissolved arsenic strongly varies from one system to another. Conservative mixing has been observed in several systems such as the Krka (Seyler and Martin, 1991), the Lena (Martin et al., 1993) or the Galway Bay (Anninou and Cave, 2009). In general, these systems are free from industrial inputs, have low particle loading and have low arsenic concentrations

\footnotetext{
* Corresponding author.

E-mail address: waeles@univ-brest.fr (M. Waeles).
}

(under $5 \mathrm{nM}$ ) in the freshwater end-member (Featherstone, 1999). Non-conservative behaviour has been also reported but removal of the metalloid seems more frequently observed than addition. Arsenic removal was observed in several European estuaries including Avon, Humber, Tamar (Langston, 1983), Scheldt (Van der Sloot et al., 1985; Andreae and Andreae, 1989) and Beaulieu River (Howard et al., 1984). In these high Fe-loaded systems, As is strongly removed under iron flocculation. In their study of the western Atlantic Ocean, Cutter et al. (2001) also suspected the intense iron oxyhydroxide scavenging for explaining the low concentrations observed in the Amazon plume. Phytoplankton development can also induce depletion of arsenic in estuarine waters. As an example, Featherstone et al. (2004) reported for a Pseudo-nitzschia bloom a removal of up to $60 \%$ of the inorganic arsenic species in the high salinity section of the Huon estuary. On the other hand, additions of arsenic were observed as the result of release froms tidal mud flats and/or sediment resuspension (e.g. Tamar and Gironde estuaries, Howard et al., 1988; Seyler and Martin, 1990). When occurring on the salinity gradient, inputs from industrial activities also lead to arsenic addition. In the Tejo estuary for example (Andreae et al., 1983), such inputs induced concentrations closed to $100 \mathrm{nM}$ at salinity 30 which is approximately five to ten times higher than the levels usually observed in coastal waters. Concentrations exceeding $1 \mu \mathrm{M}$ were reported in few systems affected by mining such as the Carnon/Retronguet estuary (Langston, 1983; Hunt and Howard, 1994) or the Tinto system (Sanchez-Rodas et al., 2005). 


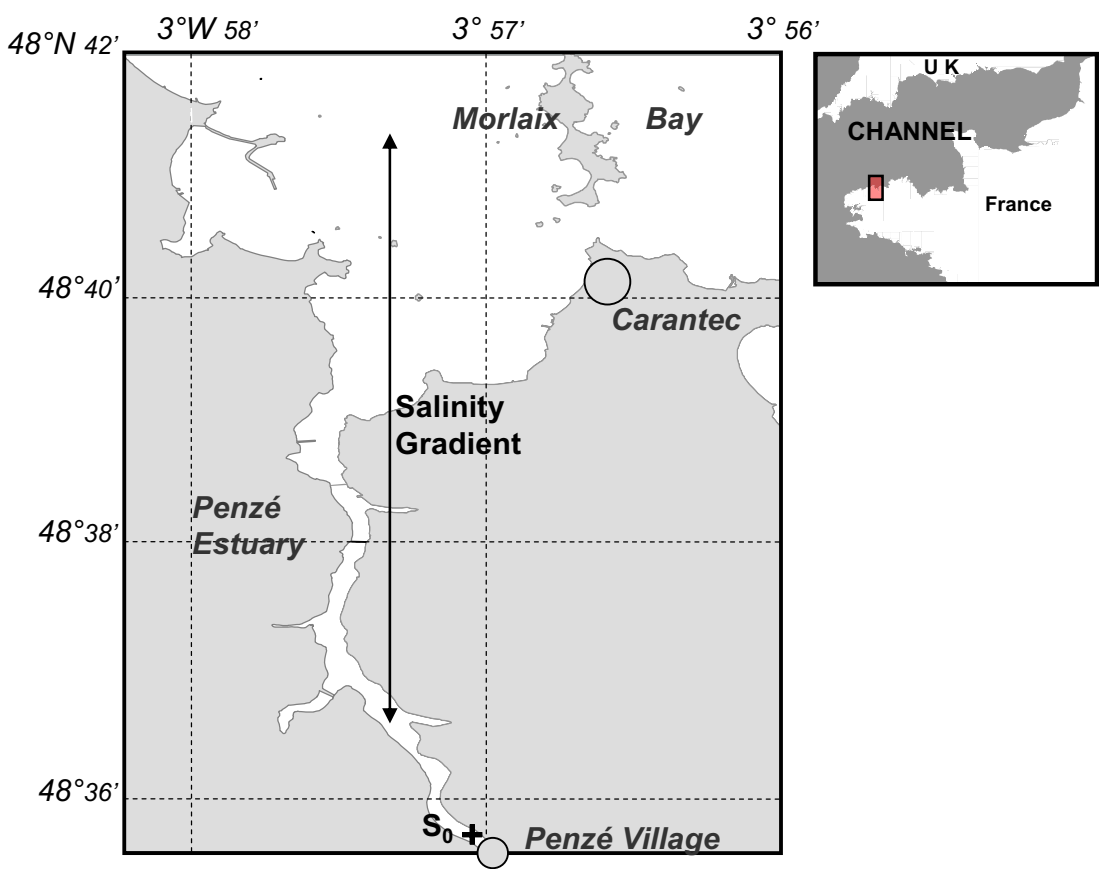

Fig. 1. Study area and approximate position of the salinity gradient during sampling conditions (neap tide, low tide).

If all these studies have provided an approach to certain essential mechanisms that govern As behaviour, the nature and density of the data reported in are sometimes limited and cannot be considered as suitably representative of the variability of an estuary (Michel et al., 1999). Indeed, very few studies have been conducted along the seasonal cycles apart those by Knox et al. (1984) and by Featherstone et al. (2004). In these two reports, the selected systems were the Tamar (UK) and the Huon (Tasmania), respectively. Because, the catchment area of the former has long been associated with intensive refining of arsenic, and because As levels in the latter are among the lowest reported anywhere, the concentrations in these two systems are not representative of the commonly encountered concentrations in estuaries.

The investigations reported here are concerned with the Penzé estuary (Brittany, western channel), a small macrotidal system that collects waters from an agricultural/poorly industrialised catchment (Waeles et al., 2005a,b). During 2008, the changes of inorganic As forms along the full range of the salinity gradient were investigated with the objective to elucidate the estuarine behaviour of the metalloid in relation with the different hydrological and biogeochemical conditions. In this paper, we report the net fluxes of the inorganic species (total and As(III)), which are considered to be the most toxic forms, and the annual budget of arsenic within the studied system is also presented.

\section{Material and methods}

\subsection{Study area}

The Penzé River (North Brittany, France) is $28 \mathrm{~km}$ long and has a drainage area of $151 \mathrm{~km}^{2}$. The water discharge at the village of Penzé generally fluctuates from 0.5 to $14 \mathrm{~m}^{3} \mathrm{~s}^{-1}$. The estuary is situated between the village of Penzé and the Morlaix Bay, covering a distance of ca. $10 \mathrm{~km}$ (Fig. 1). It is subjected to a macrotidal regime as the tidal range fluctuates between 1.8 and $9.2 \mathrm{~m}$. The residence time of water within the estuary, which is highly dependent on the tide and the river flow, varies between 2 days at spring tide and 13 days at neap tide and low discharge.

\subsection{Sampling}

Twelve cruises were conducted on a monthly basis along the salinity gradient of the Penzé estuary over the year 2008. The sampling conditions are summarised in Table 1 . Each month, at neap tide, between the stand of tide and the first flood, water samples were collected at 12 field stations between the village of Penzé and the MorlaixBay. The 12 stations were selected with the aim of covering the whole freshwater-seawater mixing zone. Approximate salinity at station $S_{i}$ was $i$. $S_{0}$ was always situated at the Penzé village in order to have a fluvial reference out from the turbid area whereas the 11 remaining locations $\left(S_{1}, S_{2}, S_{3}, S_{5}, S_{8}, S_{11}, S_{14}, S_{17}, S_{22}\right.$, $\mathrm{S}_{27}, \mathrm{~S}_{34}$ ) were situated between the haline front (around $48^{\circ} 37^{\prime} \mathrm{N}$ ) and the marine waters (above $48^{\circ} 41^{\prime} \mathrm{N}$ ). Sampling was performed from a Zodiac inflatable boat with 500-mL and 1-L-HDPE-Nalgene ${ }^{\circledR}$ bottles. Water was sampled by hand at ca. $0.5 \mathrm{~m}$ below the surface with the arm fully covered with a plastic glove $\left(92 \mathrm{~cm}\right.$, Polysem $\left.{ }^{\circledR}\right)$.

\subsection{Filtration}

Because of the relative instability of As(III), on-site filtration and preservation of this species is necessary (Sun et al., 1997).

Table 1

Sampling dates and conditions; number in bracket for water discharge indicates the variation of this parameter during the 3 days before sampling.

\begin{tabular}{lllc}
\hline Sampling date & $\begin{array}{l}\text { Water discharge } \\
\left(\mathrm{m}^{3} \mathrm{~s}^{-1}\right)\end{array}$ & Tidal range $(\mathrm{m})$ & $\begin{array}{l}\text { Temperature } \\
\left({ }^{\circ} \mathrm{C}\right)\end{array}$ \\
\hline 7-Jan & $3.17(+\mathbf{7 3} \%)$ & 5.1 & $8.3-9.2$ \\
4-Feb & $5.52(-17 \%)$ & 4.0 & $7.2-8.9$ \\
3-Mar & $2.72(+2 \%)$ & 2.3 & $9.6-10.1$ \\
1-Apr & $4.38(+15 \%)$ & 2.3 & $10.4-10.7$ \\
14-May & $2.96(+\mathbf{7 0 \%})$ & 4.1 & $14.1-14.8$ \\
13-Jun & $2.25(-8 \%)$ & 4.0 & $13.2-18.0$ \\
15-Jul & $1.26(-25 \%)$ & 4.0 & $16.0-17.3$ \\
27-Aug & $0.94(-1 \%)$ & 4.0 & $16.0-17.0$ \\
25-Sep & $1.57(+4 \%)$ & 4.1 & $12.0-15.3$ \\
23-Oct & $1.39(+3 \%)$ & 4.0 & $8.4-13.4$ \\
25-Nov & $4.86(+\mathbf{5 5 \%})$ & 5.6 & $7.6-9.1$ \\
10-Dec & $7.92(-9 \%)$ & 5.6 & $7.0-8.1$ \\
\hline
\end{tabular}


Immediately after sampling, a $125-\mathrm{mL}$ aliquot of each sample was filtered on-site with $0.45-\mu \mathrm{m}$ syringe filters ( $25 \mathrm{~mm}, \mathrm{CME}$ ). This aliquot was then spiked with $5 \mathrm{ppm}$ of hydrazine dichloride $\left(\mathrm{N}_{2} \mathrm{H}_{4} \cdot 2 \mathrm{HCl}\right.$, puriss p.a., Fluka) to avoid the oxidation of $\mathrm{As}(\mathrm{III})$ and stored at $4{ }^{\circ} \mathrm{C}$ until analysis of arsenite.

In the laboratory and within $2 \mathrm{~h}$ of sampling, the remaining nonfiltered water samples were passed through the following filters:

- 0.45- $\mu \mathrm{m}$ Millipore ${ }^{\circledR}$ HA filters were used to separate the dissolved fraction from the particles. Each membrane was introduced inside a Teflon vial for further mineralisation and determination of total particulate arsenic and lead concentrations (PAs, $\mathrm{PPb}$ ). The corresponding filtrate aliquot was acidified at $\mathrm{pH} 2\left(\mathrm{HCl}\right.$, suprapur ${ }^{\circledR}$, Merck), and then store at $4{ }^{\circ} \mathrm{C}$ until further analysis of total dissolved inorganic arsenic $\left(A s_{i}\right)$.

- 0.7- $\mu \mathrm{m} \mathrm{GF/F} \mathrm{Whatman} \mathrm{filters} \mathrm{were} \mathrm{used} \mathrm{to} \mathrm{collect} \mathrm{and} \mathrm{measure}$ particulate organic carbon (POC), chlorophyll-a (chl-a) and phaeopigments. The filters used for POC were previously ignited at $450{ }^{\circ} \mathrm{C}$ for $4 \mathrm{~h}$ and decarbonated by $\mathrm{HCl}$ fumes. Phosphate $\left(\mathrm{PO}_{4}^{3-}\right)$ was analysed on the resulting filtrates.

All filtrations and sample treatments are summarised in Fig. 2. Prior to use, all the items employed for sampling, filtration and sample storage were washed with diluted hydrochloric acid $(\mathrm{pH} 2$, $\mathrm{HCl}$ suprapur ${ }^{\circledR}$, Merck), then rinsed with Milli-Q Element ${ }^{\circledR}$ water. All filtrations and analyses were carried out in a class-100 laminar flow hood.

\subsection{Analyses of the dissolved arsenic species}

The dissolved inorganic species of arsenic, i.e. total inorganic arsenic $\left(A s_{i}\right)$ and arsenite $(\mathrm{As}(\mathrm{III}))$ were determined by stripping chronopotentiometry (SCP) with a gold film electrode. This method was developed in our laboratory and detailed in Vandenhecke et al. (2007). Briefly, As(III) the electroactive species of arsenic, is reduced in a first step to $\operatorname{As}(0)$ and simultaneous dissolved in the gold film by applying a $-300 \mathrm{mV}$ ( $\mathrm{vs} \mathrm{Ag} / \mathrm{AgCl} 3 \mathrm{M}$ ) potential for $150 \mathrm{~s}$. During the second step (stripping), As( 0 ) is re-oxyded into As(III) by application of a $1-\mu$ A constant current. From the corresponding measured signal, the quantification of arsenite is carried out by standard addition method with three spikes for each determination. For $\mathrm{As}_{\mathrm{i}}$ determination (on

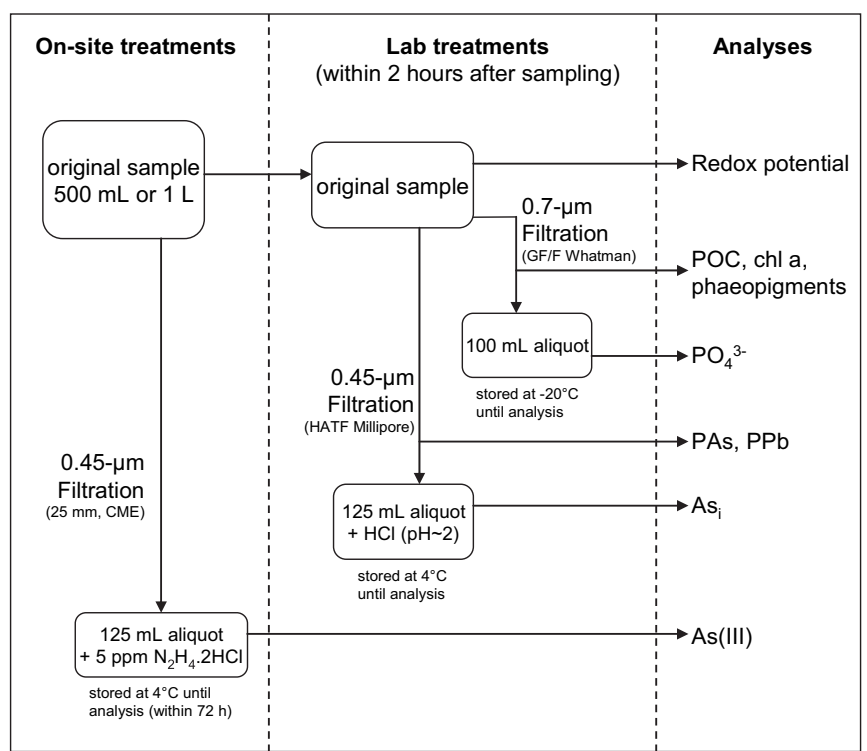

Fig. 2. Diagram of the treatments used to separate and analyse the various parameters. $0.45-\mu \mathrm{m}$-lab filtrate), a pretreatment is required to reduce $\mathrm{As}(\mathrm{V})$ into As(III) because the former species is electrochemically inert. This prereduction was chemically achieved at $80^{\circ} \mathrm{C}$ for $10 \mathrm{~min}$ by using $625 \mathrm{ppm}$ of purified L-Cysteine (for biochemistry, Merck). Then, $5 \mathrm{ppm}$ of hydrazine dichloride is added to stabilise As(III). The detection limits for $\mathrm{As}(\mathrm{III})$ and $A s_{\mathrm{i}}$ are 0.29 and $0.71 \mathrm{nM}(2.5$ and 1 min deposition time), respectively. For lower sample concentrations, deposition time can be extended to the appropriate value. Analyses of $A s_{i}$ in an estuarine certified reference material (SLEW-2) gave a $10.3 \pm 0.4 \mathrm{nM}$ $(n=5)$ concentration (certified value: $10.6 \pm 1.1 \mathrm{nM})$.

\subsection{Analyses of PAs and PPb}

Particulate metals were analysed for each month on samples $\mathrm{S}_{0}$, $S_{2}, S_{5}, S_{11}, S_{17}, S_{27}$ and $S_{34}$. A Perkin-Elmer SIMAA 6100, equipped with pyrolytic coated graphite tubes and working in the one element monochromator mode, was used for atomic absorption measurements. Samples were delivered to the furnace using a Perkin-Elmer AS-800 autosampler. Samples were directly taken from acid-washed cups. $5 \mu \mathrm{L}$ of $1 \mathrm{~g} \mathrm{Pd}$, as $\mathrm{Pd}\left(\mathrm{NO}_{3}\right)_{2}$, was used as chemical modifier. Determination of particulate As has been conducted according to the method developed by Cabon and Cabon (2000), the light source was an As EDL system 2 operating at $380 \mathrm{~mA}$, using the $193.7 \mathrm{~nm}$ resonance line. For the determination of $\mathrm{Pb}$, the light source was a $\mathrm{Pb}$ EDL system 2 operating at $450 \mathrm{~mA}$, using the $283.3 \mathrm{~nm}$ resonance line. The inert gas was argon.

To determine particulate arsenic concentrations (PAs, Fig. 2), $7 \mathrm{~mL}$ of $\mathrm{HNO}_{3} / \mathrm{HF}(5: 2)$ mixture was added to each of the filters. Then, the Teflon vials were placed on a hot plate at $100{ }^{\circ} \mathrm{C}$ until the acid mixture was evaporated. After repeating once more this procedure, the samples were redissolved in $20 \% \mathrm{HNO}_{3}$ and reheated for $3 \mathrm{~h}$ at $100{ }^{\circ} \mathrm{C}$. The aliquots were then diluted in $20 \mathrm{~mL}$ of ultrapure water. Samples of 100 -mg certified reference sediment (PACS-2) and blank filters were treated following the outlined procedure. In the case of arsenic, the recovery obtained for the reference material was $96 \pm 7 \%(n=3)$. Blanks were less than $10 \%$ of the lowest sample concentrations.

\subsection{Other measurements}

Salinity $(S)$ and temperature $(T)$ were in-situ measured with a WTW ProfiLine LF 197 probe ( \pm 0.1 and $0.1{ }^{\circ} \mathrm{C}$, precisions). Redox potential $(E)$ was measured with a combined Pt electrode with $\mathrm{Ag}$ / $\mathrm{AgCl} / \mathrm{KCl}(3 \mathrm{M})$ as a reference system $( \pm 10 \mathrm{mV}$, precision). Particulate Organic Carbon (POC) was assessed using a ThermoQuest - FlashEA CHN analyser. Precision on POC quantification was about $5 \%$.

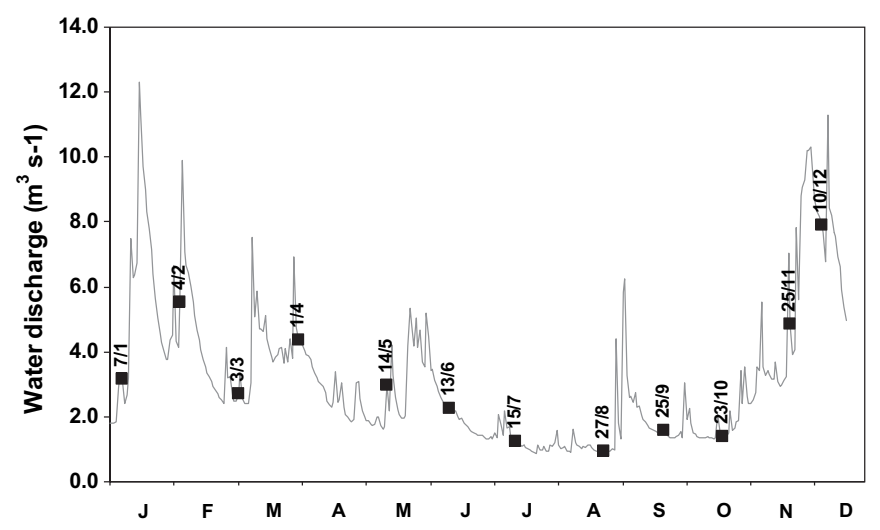

Fig. 3. Seasonal water discharge (Penhoat field station, Agence de l'eau Loire-Bretagne) and dates of sampling (see also Table 1 ). 

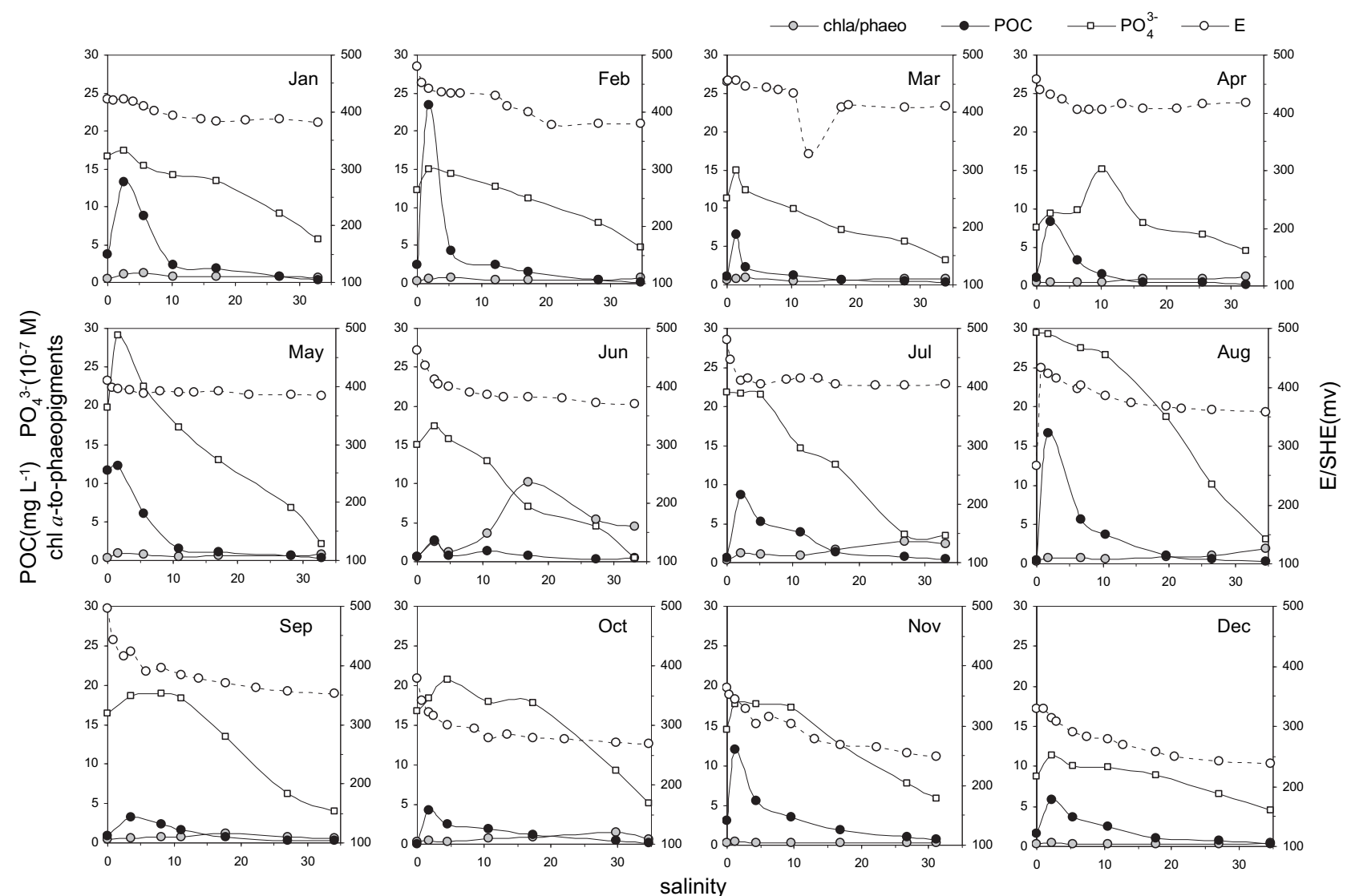

salinity
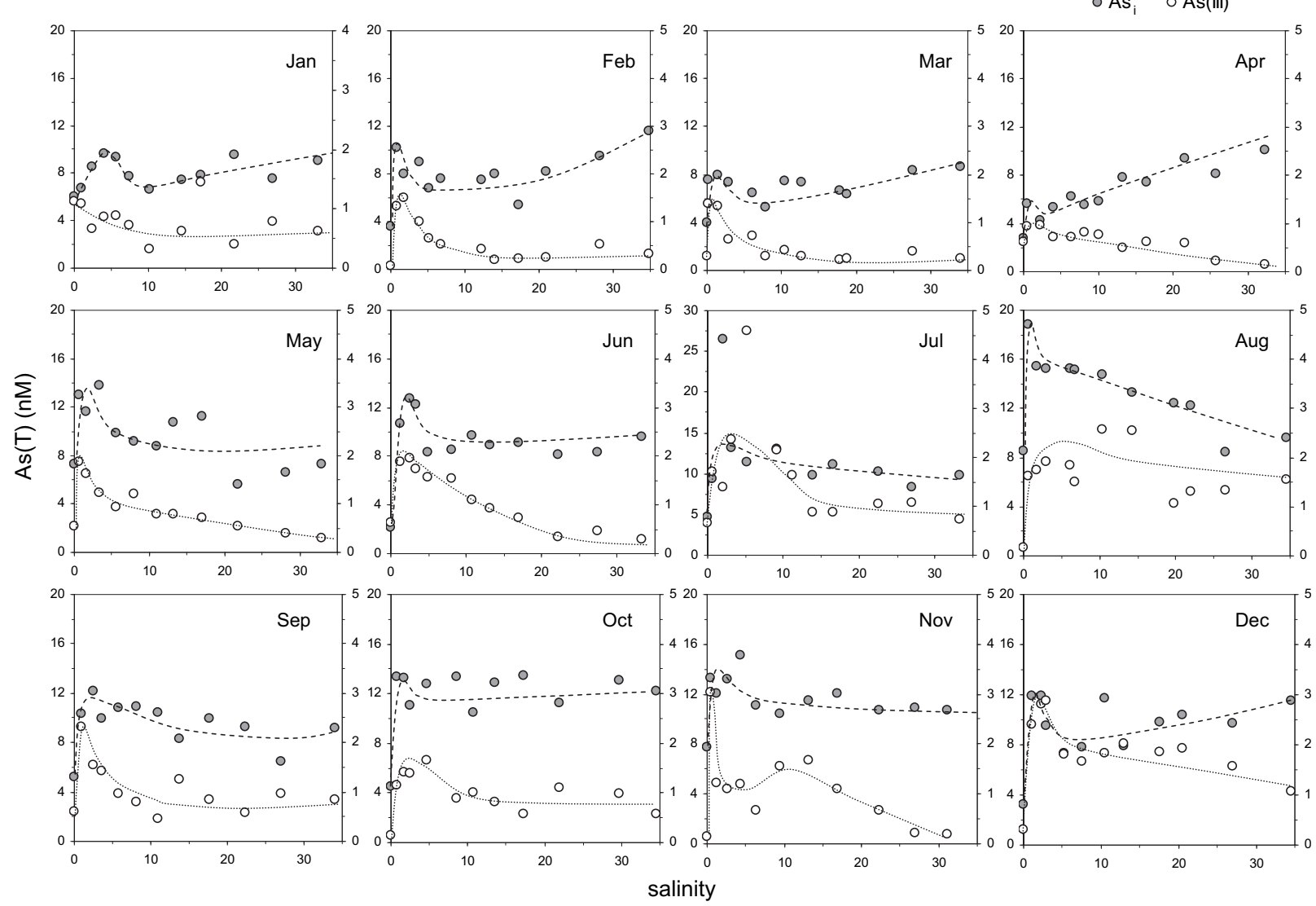

Fig. 4. (a) $\mathrm{POC}, \mathrm{PO}_{4}^{3-}$, chl-a-to-phaeopigments and $\mathrm{E} / \mathrm{SHE}$, (b) $\mathrm{As}_{\mathrm{i}}$ and $\mathrm{As}(\mathrm{III}),(\mathrm{c}) \mathrm{PAs}$ and $\mathrm{PPb}$ salinity distributions over the seasonal cycle. 


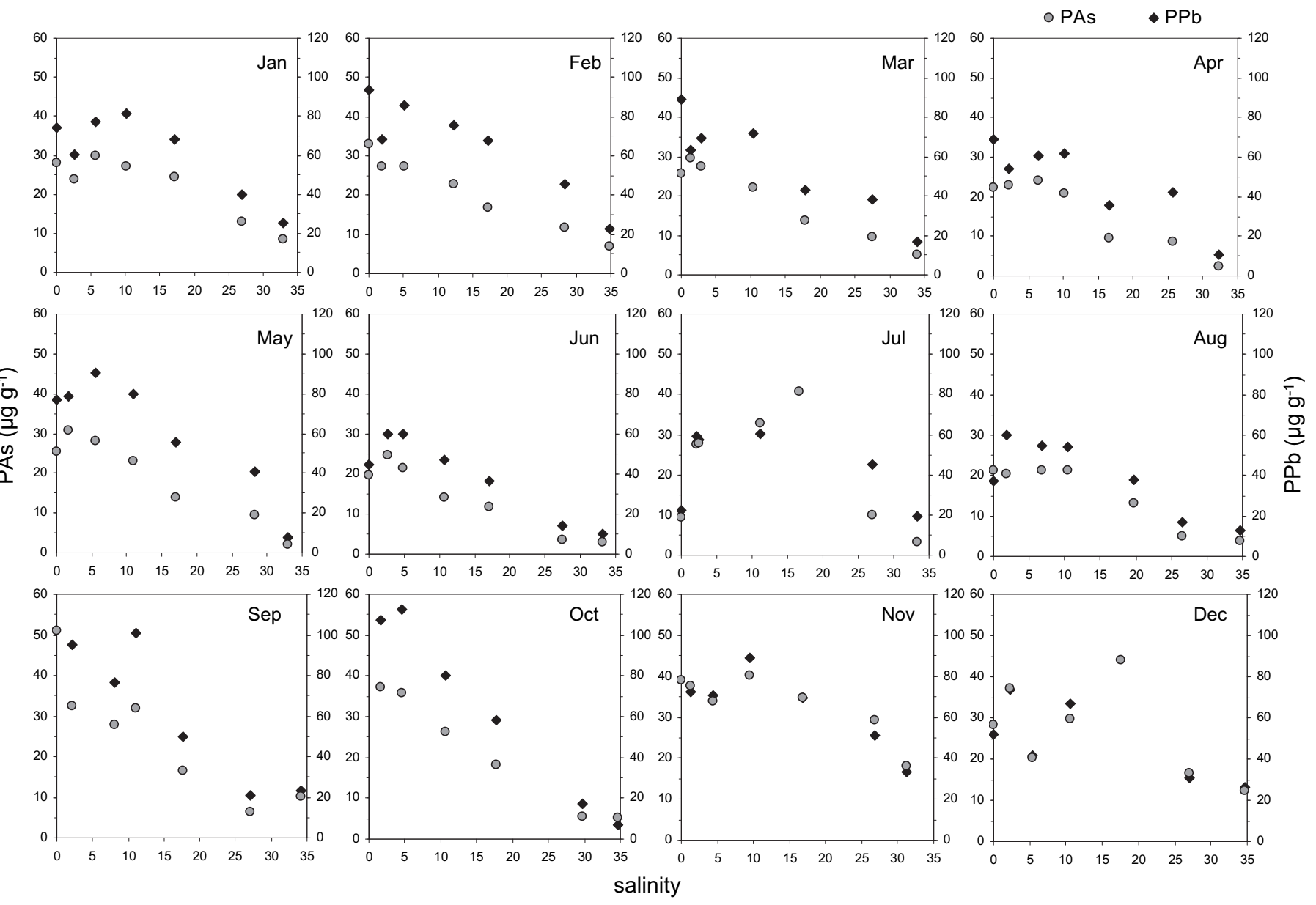

Fig. 4. (continued).

Chlorophyll- $a$ and phaeopigments were extracted and measured by Lorenzen's method (Lorenzen, 1967) with an 8\% precision. Phosphate concentrations were determined using the Murphy and Riley (1962) method $( \pm 0.02 \mu \mathrm{M}$, precision).

\section{Results and discussion}

\subsection{Seasonal variations of the hydrological and biogeochemical characteristics}

Fig. 3 illustrates the daily water discharge of the Penzé River over the year 2008 and shows fluctuation between 1.0 and $12.3 \mathrm{~m}^{3} \mathrm{~s}^{-1}$. On few occasions, sampling was conducted under strong elevation of the discharge (January, May and November, see also Table 1).

Biogeochemical variables were plotted against salinity for each sampling campaign (Fig. 4a). POC concentrations were in the range $0.1-23 \mathrm{mg} \mathrm{L}^{-1}$. The maximum concentrations were always found in the low-salinity area and are linked to the accumulation of particles close to the haline front. Such an accumulation of particles ensues from the tidal asymmetry and is a common feature of macrotidal estuaries (Jay and Musiak, 1994; Brenon and Le Hir, 1999). According to the variations of the chl-a-to-phaeopigments ratio, phytoplanktonic species in good physiological conditions were encountered only in June in the downstream section of the estuary $(S>10)$.

The redox potential varied in the range $240-500 \mathrm{mV}$ vs SHE and was usually high confirming that the Penze estuary is a welloxygenated system. However, one should note the occurrence of suboxic conditions in autumn. Phosphate levels were in the range
$0.04-2.94 \mu \mathrm{M}$. Concentrations in fluvial waters were generally above $1 \mu \mathrm{M}$ and decreased along the salinity gradient. Phosphate had in all cases a non-conservative behaviour with a positive deviation from linearity indicative of additions. These additions that occurred in the low-salinity section were attributed to releases from the sediment. Indeed, according to the study by Andrieux-Loyer et al. (2008), phosphate inputs from the benthic compartment of the Penzé estuary represent, on occasion, up to $50 \%$ of river loadings.

\subsection{As behaviour during estuarine mixing}

Variations of $A s_{i}$ and $A s($ III) along the salinity gradient are presented for each month in Fig. $4 \mathrm{~b}$. For $A s_{\mathrm{i}}$, concentrations were in the range 2.2-26 nM with values being on the same order for fluvial and marine end-members. Analysis of the $\mathrm{As}_{\mathrm{i}}$-salinity diagrams revealed, for each month, deviations from the theoretical dilution lines. At first, there is generally an increase of the concentrations between $S_{0}$ and the haline front, with maximum levels encountered at $S_{1}$ (February, August, October, and December), $S_{2}$ (March, June, July and September) or $\mathrm{S}_{3}$ (January, May and November). The increases of $A s_{i}$ in the range 2.9-22 nM compared to fluvial concentrations of 2.2-8.6 nM, were thus particularly strong. The positive deviations from linearity associated with these strong increases indicate inputs of the dissolved element between the Penzé village $\left(\mathrm{S}_{0}\right)$ and the haline front.

From the low-salinity arsenic maximum, concentrations of $\mathrm{As}_{\mathrm{i}}$ did not behave conservatively. A more or less pronounced negative deviation is observed in the remaining gradient suggesting a removal of the dissolved inorganic As species to the particulate 
phase. This removal, where present, appears to occur in the salinity range ca. $2-10$.

$\mathrm{As}(\mathrm{III})$ concentrations varied from 0.1 to $4.6 \mathrm{nM}$; this form representing between 2 and $40 \%$ of the inorganic species. As for Asi, As (III) behaved non-conservatively with a strong addition (increases of $0-3.9 \mathrm{nM}$ ) between $\mathrm{S}_{0}$ and the very low-salinity area. At higher salinities, As(III) concentrations decreased and a removal of this form is also noticeable in the remaining salinity gradient.

As concentrations in particles (PAs) were in the range 3.3 $-56 \mu \mathrm{g} \mathrm{g}^{-1}$ (Fig. 4c). The highest concentrations were generally observed in the inner estuary (salinity range $0-10$ ) with values over $20 \mu \mathrm{g} \mathrm{g}^{-1}$. No clear trend was apparent in this area although one can suspect positive deviations in some occasions (April to August). Above salinity 10, PAs levels decreased seaward, probably as the result of mixing of particles of different nature/origin; the levels in marine waters were generally under $10 \mu \mathrm{g} \mathrm{g}^{-1}$. PPb concentrations (Fig. 4c) varied in the same way with high levels being encountered in the upstream part and decreasing concentrations from salinity 10 onwards.

\subsubsection{Addition of dissolved As}

Dissolved arsenic positive deviations in estuaries have been interpreted as the result of various inputs. Inputs from pollutant sources, mostly by industrial activities have been evidenced in the salinity gradient of some estuaries: e.g. the Tejo (Andreae et al., 1983) or the Scheldt (Van der Sloot et al., 1985). Because no industries are present along the Penze system, such a cause of deviation can be ruled out here.

Inputs of inorganic arsenic following mineralisation of biological material have been evidenced in the high turbidity zone (HTZ) of the Seine estuary. According to their study, Michel et al. (2001) indicated that this process was the result of $\mathrm{As}(\mathrm{V})$ pumping in high salinity waters and further incorporation of the plankton particles in the HTZ. In the Penze estuary, even in June when the maximum of chl-a-to-phaeopigments ratio was observed (Fig. 4a) no any removal of dissolved As that could correspond to phytoplanktonic absorption of the metalloid was found. Moreover, our results about PAs indicated that arsenic content in organic particles does not exceed $6 \mu \mathrm{g} \mathrm{g}^{-1}$ : This latter concentration was estimated from a linear regression between PAs and $\mathrm{PPb}$ data which gave: $\mathrm{PAs}=0.50 \mathrm{PPb}+6.4, r^{2}=0.73, p<0.01, n=84$. Following the hypothesis that particulate organic arsenic remineralization is total, a $30-500 \mathrm{mg} \mathrm{L}^{-1}$ particulate organic matter concentration is necessary for explaining the increase in dissolved As, which is far beyond the observed POC concentrations $\left(0.1-23 \mathrm{mg} \mathrm{L}^{-1}\right)$.

The possibility of an As desorption from the particulate phase is also poorly supported by the PAs data. Indeed, no any loss in As concentration in particle corresponded to the strong inputs of dissolved species.

As reported for many estuaries (Andreae et al., 1983; Knox et al., 1984; Van der Sloot et al., 1985; Andreae and Andreae, 1989; Seyler and Martin, 1990; Yao et al., 2006), inputs from the benthic compartment appear to be the most probable source of dissolved As. The studies by Andrieux-Loyer et al. (2008) and Lerat (1990) in the Penze system showed that high phosphate and $\mathrm{NH}_{4}^{+}$are also supplied from the sediment. Because concomitant releases of $\mathrm{NH}_{4}^{+} / \mathrm{PO}_{4}^{3-}$ and As were reported in interstitial waters of other systems (Knox et al., 1984; Krom and Berner, 1986; Peterson and Carpenter, 1986; Mucci et al., 2000) one can expect substantial As benthic fluxes injection in the water column of the Penze estuary. It is worth noting also that $\mathrm{PO}_{4}^{3-}$ behaviour in the mixing zone (Fig. 4a) showed positive deviations in the same area than $\mathrm{As}_{\mathrm{i}}$ inputs in almost all cases.

The release of arsenic from sediment can occur in different steps (Edenborn et al., 1986; Maher and Butler, 1988). At first, arsenic is desorbed into porewaters following the reduction and the dissolution of hydrous Fe or Mn phases. Then, the supply of metalloid into the overlying waters occurs through diffusion or through compactation of sediments that forces porewaters upwards. It has been suggested (Maher and Butler, 1988 and references therein) that diffusion processes are probably limited in term of As release to the water column because the redox boundary within the sediment column acts as a barrier (As being readsorbed within the oxic sediment). However, surficial mixing of the sediment can overcome this barrier thus explaining why important As fluxes from sediment (and large positive deviations) are observed in macrotidal estuaries (e.g. Tamar estuary: Langston, 1983; Knox et al., 1984; Gironde estuary: Seyler and Martin, 1990; Michel et al., 2000 and Geum estuary: Byrd et al., 1990). Enhancement of As mobilisation by biological activity has also been demonstrated. According to the studies by Riedel et al. (1987, 1989), burrowing organisms significantly affects distribution and flux of arsenic from the sediments.

According to our data, inputs of dissolved As, probably from sediments, release both $\mathrm{As}(\mathrm{V})$ and $\mathrm{As}(\mathrm{III})$ species. Increases of $A s_{i}$ concentrations between $S_{0}$ and maxima $\left(S_{1}, S_{2}\right.$ or $\left.S_{3}\right)$ were in the range $2.9-21.7 \mathrm{nM}(8.2 \pm 2.8 \mathrm{nM}, \mathrm{CI} 95 \%, 0.05, n=12)$ whereas increases of $\mathrm{As}(\mathrm{III})$ concentrations varied from 0.0 to $3.9 \mathrm{nM}$ $(1.7 \pm 0.7 \mathrm{nM}, \mathrm{CI} 95 \%, 0.05, n=12)$. Thus, the contribution of $\mathrm{As}(\mathrm{III})$ in the increase of $A s_{i}$ throughout the studied year was $16 \pm 5 \%$. This is in agreement with previous studies showing that both forms are present in interstitial waters from coastal sediments. In these studies, As(III) accounting generally for $5-30 \%$ of the total As depending to the area of sampling (Andreae, 1979; Knox et al., 1984; Peterson and Carpenter, 1986).

The two significant increases of the $\mathrm{As}(\mathrm{III}) / \mathrm{As}_{\mathrm{i}}$ ratio observed in summer and at the end of autumn should be related to a strong input of As(III) at these periods. An increase of the As(III) concentrations exceeding $2.0 \mathrm{nM}$ in the water column was observed in July, August, November and December. However, high $\mathrm{As}(\mathrm{III}) / \mathrm{As}_{\mathrm{i}}$ ratios in the Penze estuary are probably not only controlled by benthic inputs but should also be related to the conditions that contribute to stabilise arsenite. The reducing conditions reported at the end of autumn over the whole estuary are in favour of As(III) stabilisation. Other parameters that would influence stabilisation or oxidation of As(III) are temperature, salinity, iodate concentration, light or bacteria composition (Cullen and Reimer, 1989; Quentel et al., 2006 and references therein).

\subsubsection{Removal of dissolved As}

The absorption of dissolved As by phytoplanktonic species (i.e. Pseudo-nitzschia) has been highlighted in the Huon estuary (Featherstone et al., 2004) and suspected in the Pearl River estuary (Froelich et al., 1985). In the Penzé estuary, such a mechanism is hardly probable for explaining As elimination because the metalloid redistribution occurred in the salinity range $0-10$ and was observed at almost all seasons. In particular, during the June bloom which took place in the salinity range $10-30$, no significant removal of dissolved As or increase of particulate As was observed.

The removal of dissolved As in our system is more probably linked to the co-precipitation of As with iron oxides as a consequence of $\mathrm{pH}$ and salinity increase as proposed by several authors (Langston, 1983; Howard et al., 1984, 1988; Van der Sloot et al., 1985; Elbaz-Poulichet et al., 2000). In the Penzé estuary, the precipitation of iron at low salinities is a well-identified mechanism (Riso et al., 2006) that is responsible for the removal of $\mathrm{Pb}$ by co-precipitation (Waeles et al., 2007). The strong correlation observed between PAs and $\mathrm{PPb}$ in the present study $\left(\mathrm{PAs}=0.50 \mathrm{PPb}+6.4, r^{2}=0.73, p<0.01\right.$, $n=84$ ) indicates that co-precipitation of As with iron oxides is the dominant process that removes the metalloid from solution in the Penzé estuary. This process may also explain the positive deviation occasionally observed for PAs in the salinity range 0-10. 
Table 2

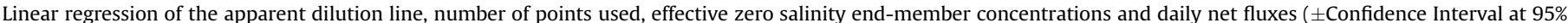
level).

\begin{tabular}{|c|c|c|c|c|c|c|c|c|c|}
\hline \multirow[b]{2}{*}{ Sampling date } & \multirow[b]{2}{*}{$Q\left(\mathrm{~m}^{3} \mathrm{~s}^{-1}\right)$} & \multicolumn{4}{|l|}{$A s_{i}$} & \multicolumn{4}{|l|}{$\mathrm{As}(\mathrm{III})$} \\
\hline & & Linear regression & $n$ & $\mathrm{C}_{0}^{\prime} \pm \mathrm{CI} 95 \%(\mathrm{nM})$ & $\mathrm{F}_{\mathrm{S}} \pm \mathrm{CI} 95 \%\left(\mathrm{~g} \mathrm{~d}^{-1}\right)$ & Linear regression & $n$ & $\mathrm{C}_{0}^{\prime} \pm \mathrm{CI} 95 \%(\mathrm{nM})$ & $\mathrm{F}_{\mathrm{S}} \pm \mathrm{CI} 95 \%\left(\mathrm{~g} \mathrm{~d}^{-1}\right)$ \\
\hline 7-Jan & 3.17 & $A s_{i}=0.032 S+7.6$ & 12 & $8 \pm 2$ & $160 \pm 40$ & $\mathrm{As}(\mathrm{III})=-0.0083 \mathrm{~S}+0.89$ & 12 & $0.9 \pm 0.3$ & $18 \pm 8$ \\
\hline 4-Feb & 5.52 & $A s_{i}=0.087 S+6.9$ & 10 & $7 \pm 2$ & $250 \pm 80$ & $\mathrm{As}(\mathrm{III})=-0.0058 \mathrm{~S}+0.49$ & 8 & $0.5 \pm 0.3$ & $20 \pm 20$ \\
\hline 3-Mar & 2.72 & $\mathrm{As}_{\mathrm{i}}=0.033 \mathrm{~S}+6.8$ & 11 & $7 \pm 2$ & $120 \pm 30$ & $\operatorname{As}(\mathrm{III})=-0.0017 \mathrm{~S}+0.34$ & 7 & $0.3 \pm 0.2$ & $6 \pm 4$ \\
\hline 1-Apr & 4.38 & $A s_{i}=0.16 S+4.8$ & 11 & $5 \pm 1$ & $140 \pm 30$ & $\mathrm{As}(\mathrm{III})=-0.024 \mathrm{~S}+0.94$ & 11 & $0.9 \pm 0.2$ & $27 \pm 5$ \\
\hline 14-May & 2.96 & $A s_{i}=-0.19 S+12$ & 11 & $12 \pm 2$ & $230 \pm 50$ & $\operatorname{As}(\mathrm{III})=-0.024 \mathrm{~S}+1.1$ & 6 & $1.1 \pm 0.1$ & $21 \pm 4$ \\
\hline 13-Jun & 2.25 & $A s_{i}=0.010 S+8.7$ & 8 & $9 \pm 2$ & $130 \pm 30$ & $\mathrm{As}(\mathrm{III})=-0.0056 \mathrm{~S}+1.9$ & 11 & $1.9 \pm 0.3$ & $27 \pm 5$ \\
\hline 15-Jul & 1.26 & $A s_{i}=-0.12 S+13$ & 9 & $13 \pm 2$ & $100 \pm 20$ & $\mathrm{As}(\mathrm{III})=-0.0024 \mathrm{~S}+0.97$ & 5 & $1.0 \pm 0.8$ & $8 \pm 7$ \\
\hline 27-Aug & 0.94 & $A s_{i}=-0.22 S+16$ & 10 & $16 \pm 2$ & $100 \pm 10$ & $\operatorname{As}(\mathrm{III})=-0.015 \mathrm{~S}+1.9$ & 11 & $1.9 \pm 0.5$ & $12 \pm 4$ \\
\hline 25-Sep & 1.57 & $A s_{i}=-0.10 S+11$ & 11 & $11 \pm 2$ & $110 \pm 20$ & $\mathrm{As}(\mathrm{III})=-0.015 \mathrm{~S}+1.2$ & 10 & $1.2 \pm 0.5$ & $12 \pm 5$ \\
\hline $23-$ Oct & 1.39 & $A s_{i}=-0.006 S+13$ & 11 & $13 \pm 2$ & $110 \pm 20$ & $\mathrm{As}(\mathrm{III})=-0.020 \mathrm{~S}+1.3$ & 11 & $1.3 \pm 0.3$ & $12 \pm 4$ \\
\hline 25-Nov & 4.86 & $A s_{i}=0.083 S+13$ & 11 & $13 \pm 2$ & $410 \pm 60$ & $\mathrm{As}(\mathrm{III})=-0.033 \mathrm{~S}+1.4$ & 10 & $1.4 \pm 0.5$ & $40 \pm 20$ \\
\hline 10-Dec & 7.92 & $A s_{i}=0.016 S+9.7$ & 11 & $10 \pm 2$ & $500 \pm 120$ & $\mathrm{As}(\mathrm{III})=-0.039 \mathrm{~S}+2.5$ & 11 & $2.5 \pm 0.4$ & $130 \pm 30$ \\
\hline
\end{tabular}

As (III) and $\mathrm{As}_{\mathrm{i}}$ are both removed in the salinity range $0-10$ suggesting that co-precipitation with iron oxides concern all As inorganic species (V + III). In the Tamar estuary, Knox et al. (1984) also noticed the analogy between dissolved Fe and As(III). However, these authors do not exclude that $\mathrm{As}(\mathrm{III})$ removal occurred as an oxidation to $\mathrm{As}(\mathrm{V})$ catalysed by hydrous manganese oxide. According to Mn behaviour, this oxidative process should be particularly effective in the turbidity maximum area and should produce low $\mathrm{As}(\mathrm{III}) / \mathrm{As}_{\mathrm{i}}$ ratios in this area compared to upstream ones. In the Penzé estuary, comparison of As (III)/As $s_{i}$ ratios between $S_{0}$ (Penzé village) and $S_{1} / S_{2}$ stations indicated that no significant variations were observed within freshwater until the maximum turbidity zone. At $\mathrm{S}_{0}, \mathrm{As}(\mathrm{III}) / \mathrm{As}_{\mathrm{i}}$ was $11 \pm 4 \%(\mathrm{CI} 95 \%$, $0.05, n=12$ ) whereas at $\mathrm{S}_{1}$ and $\mathrm{S}_{2}, \mathrm{As}(\mathrm{III}) / \mathrm{As}_{\mathrm{i}}$ were $17 \pm 3 \%$ and $14 \pm 4 \%$, respectively.

The fact that dissolved As removal was on occasion not obvious (in particular in the case of April, September and October) should result from the competition between As inputs from sediment and As elimination by co-precipitation with iron oxides. Benthic inputs are bound to occur over the area where fine particles settle $\left(48^{\circ} 36.2-48^{\circ} 38.0 \mathrm{~N}\right.$, Tessier comm. pers) whereas As removal always occurs at a given salinity range (i.e. $0-10$ ). The neap tide conditions that were chosen for our sampling are in favour of As benthic inputs in areas covered by fluvial waters or by very low-salinity waters, thus explaining why dissolved As along was first added then removed. One should anticipate that the two processes affecting As during its transport seaward can be superimposed or occur in different order according to the position of the salinity gradient.

\subsection{Fluxes}

Daily input and output fluxes of the As inorganic species were estimated for the water column of the Penze estuary. They were calculated by multiplying the daily river discharge $Q$ with specific concentrations; this is described as follows:

$$
\begin{gathered}
F_{I}=Q^{*} C_{0} \\
F_{O}=Q^{*} C_{0}^{\prime} \\
F_{A}=Q^{*}\left(C_{M}-C_{0}\right) \\
F_{R}=Q^{*}\left(C_{M}-C_{0}^{\prime}\right)
\end{gathered}
$$

Inputs from the river $\left(\mathrm{F}_{\mathrm{I}}\right)$ were deduced from concentrations at $\mathrm{S}_{0}\left(\mathrm{C}_{0}\right)$. Outputs to the sea (net fluxes, $\mathrm{F}_{\mathrm{O}}$ ) were determined from effective zero salinity end-member concentrations $\left(\mathrm{C}_{0}{ }^{\prime}\right)$ according to Boyle et al. (1974) method by fitting a linear regression between concentrations and salinity at the point where $A s_{i}$ and $\mathrm{As}(\mathrm{III})$ species become conservative. The selection of the conservative area is a critical step. Usually, it is determined in order to maximize the correlation coefficient (e.g. Michel et al., 2000; De Gieter et al., 2005; Yao et al., 2006; Dabrin et al., 2009). However, this procedure is not satisfactory when little variations of the concentrations occur along the salinity gradient as in our systems: i.e. in the case of mixing of water masses with very similar concentrations of the considered element, even a strong linearity would result in

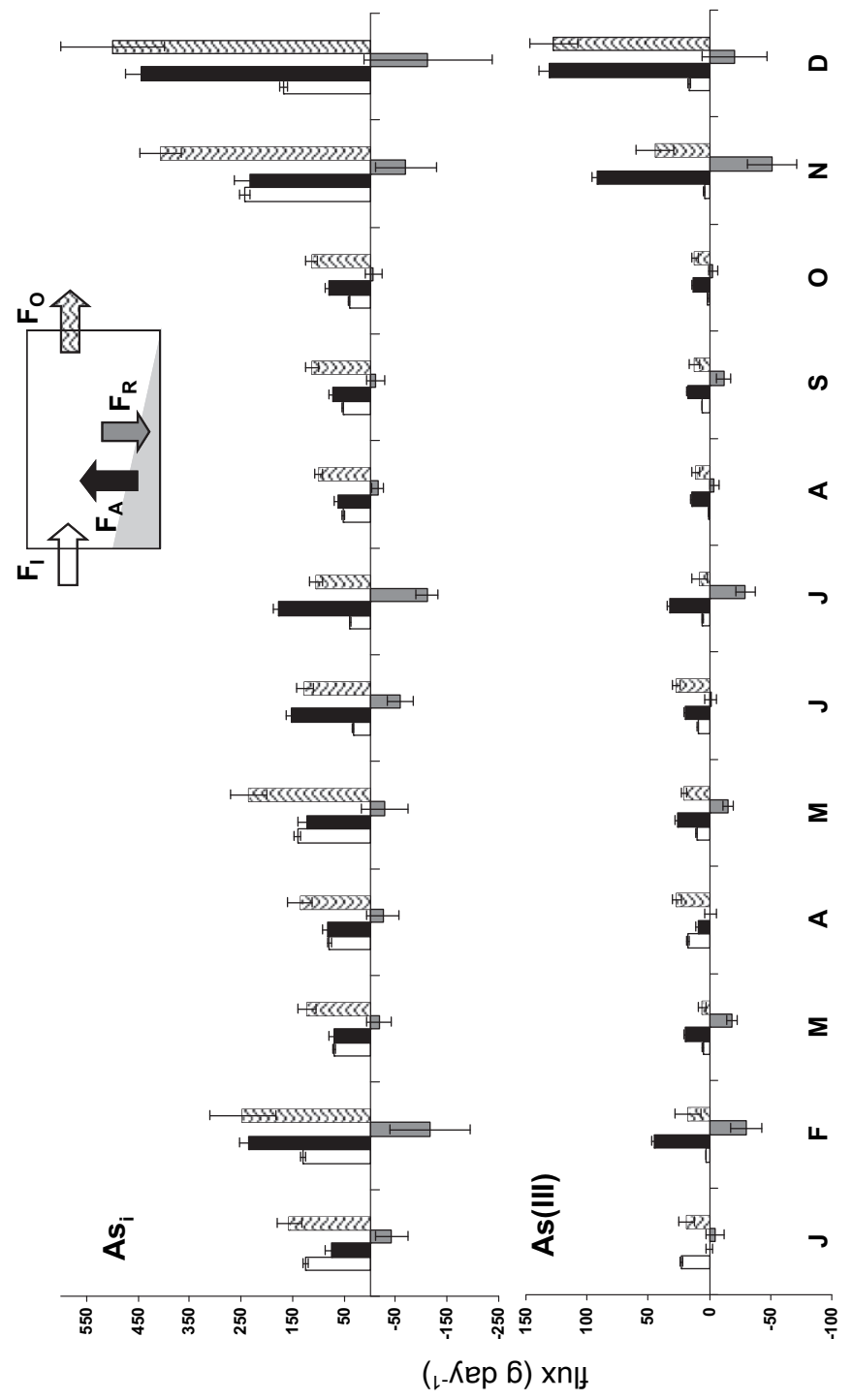

Fig. 5. Fluxes of $A s_{i}$ and $A s(I I I)$ species in the Penzé estuary. White, black, grey and striped bars correspond to $F_{1}$ (inputs from river), $F_{A}$ (addition within the estuary), $F_{R}$ (removal) and $\mathrm{F}_{\mathrm{O}}$ (net fluxes to the coastal area), respectively. 


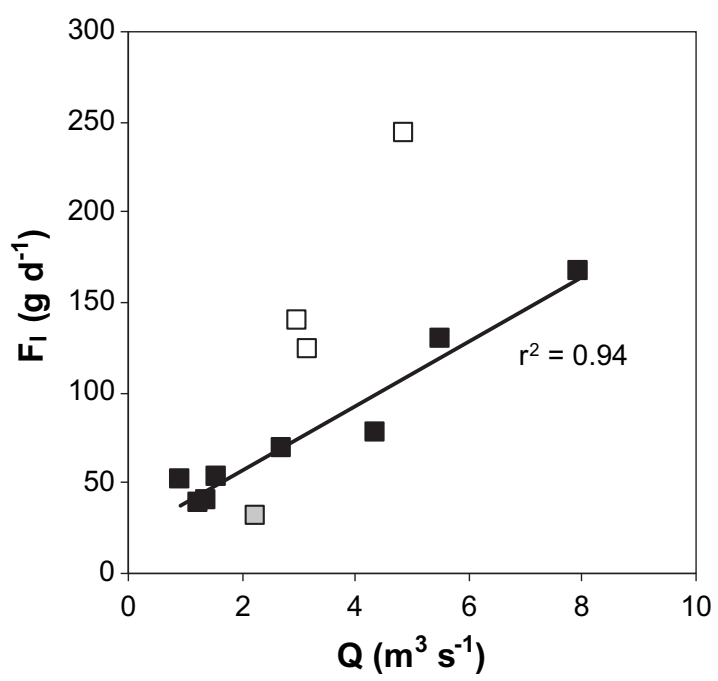

Fig. 6. Relationship between fluxes of dissolved As from the Penzé river and the freshwater discharge. White squares correspond to periods of heavy precipitation which resulted in high variation of the water discharge (i.e. samplings of January, May and November, see Table 1); the grey square correspond to the June sampling (period of high phytoplanktonic production).

poor correlation coefficients. Thus, the conservative area was chosen in the case of this study in order to obtain the lowest 95\% confidence interval on each intercept (Table 2).

Dissolved As flux exchanges between sediment/particles and water column were also assessed. Additions within the estuary $\left(F_{A}\right)$ were deduced from the resulting positive deviations observed on $A s_{i}$ and $A s(I I I)$ species. For each situation, the difference between maximum concentrations ( $C_{M}$, that where found at $S_{1}, S_{2}$ or $S_{3}$ ) and $S_{0}$ concentrations $\left(C_{0}\right)$ was used and any dilution effect was neglected over this low-salinity range. Removal fluxes $\left(F_{R}\right)$ that consist of As transfer to the particulate phase and the sediment were obtained using the difference between $C_{M}$ and $C_{0}{ }^{\prime}$.

Fig. 5 describes the various daily input and output fluxes. $A s_{i}$ inputs from the river varied between $32 \pm 1$ and $244 \pm 10 \mathrm{~g} \mathrm{~d}^{-1}$ with minimum amounts during summer months (June-October) and maximum amounts in winter (especially in November and December). Variations of these fluxes were relatively well correlated with that of water discharge $\left(F_{I}=18 Q+21, r^{2}=0.94, p<0.05\right)$ as illustrated by Fig. 6. However, in periods of heavy precipitation which resulted in high variation of the water discharge (i.e. samplings of January, May and November, see Table 1), positive deviations from this relation were observed (white squares). As

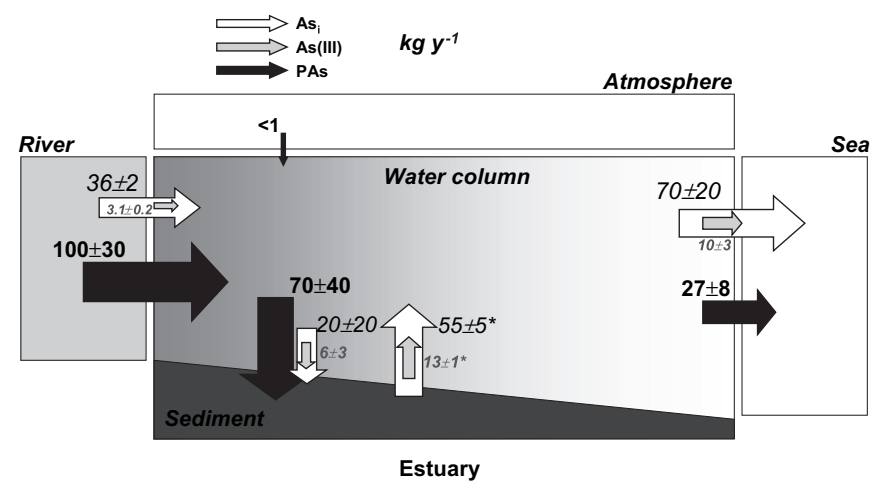

Fig. 7. As budget of the Penzé estuary in neap tide conditions (fluxes in $\mathrm{kg} \mathrm{y}^{-1}$ ). *Although not directly measured, additions of dissolved inorganic As within the estuary have been attributed to the benthic inputs which are the most probable. mentioned by Michel et al. (2000) for the Gironde, additional inputs of arsenic in the river may arise from the mobilisation of contaminated soil particles/sediments and the transfer of the metalloid to the dissolved phase. The negative deviation observed in June (grey square), that is usually the period of higher primary production in Brittany rivers, could corresponds to phytoplankton uptake. As(III) inputs fluctuated from $1.0 \pm 0.1$ and $23 \pm 1 \mathrm{~g} \mathrm{~d}^{-1}$. Thus, the relative importance of $A s(\mathrm{III})$ in the inorganic fluxes was in the range $2-29 \%$.

According to our estimations, As $\mathrm{s}_{\mathrm{i}}$ outputs to the sea varied from $100 \pm 10$ to $500 \pm 100 \mathrm{~g} \mathrm{~d}^{-1}$ with minimum amounts in summer and maximum amounts in winter. As(III) outputs were in the range $6 \pm 4-130 \pm 30 \mathrm{~g} \mathrm{~d}^{-1}$ and represented between 5 and $26 \%$ of the $\mathrm{As}_{\mathrm{i}}$ fluxes. It is worth noting than these net $\mathrm{As}_{\mathrm{i}}$ and $\mathrm{As}$ (III) fluxes were always higher than the fluvial inputs. Thus, the supply of dissolved arsenic within the estuary $\left(\mathrm{F}_{\mathrm{A}}\right)$ always prevail its removal to the particulate phase $\left(\mathrm{F}_{\mathrm{R}}\right)$.

This call into question the assumption that estuaries are a sink of this metalloid (Maher and Butler, 1988; Cullen and Reimer, 1989; Smedley and Kinniburgh, 2002). As a matter of fact, strong As inputs from the sediment appear to be a common feature of the macrotidal systems (Kitts et al., 1994; De Gieter et al., 2005; Yao et al., 2006; Masson et al., 2009).

The annual budget of dissolved inorganic arsenic in the Penzé estuary has been achieved (Fig. 7). The various input and output daily fluxes were accumulated and extrapolated to one year. The representativeness of the sampling in terms of water discharge conditions was verified: the average discharge for 2008 was $3.3 \pm 2.2 \mathrm{~m}^{3} \mathrm{~s}^{-1}(n=365)$ whereas the average discharge for the 12 sampling campaigns was $3.1 \pm 2.1 \mathrm{~m}^{3} \mathrm{~s}^{-1}(n=12)$. Yearly particulate fluxes were estimated from the sediment budget of the Penzé estuary (Verney et al., 2008) and from fluvial and marine average PAs concentrations. Fluxes from the atmosphere were assessed using the Austin and Millward (1986) study about atmospheric-coastal ocean exchange of particulate arsenic.

Our results showed that As was imported from the river mainly as particulate, PAs flux accounting for $\sim 75 \%$ of the total flux. As(III) species accounted for $\sim 10 \%$ of the dissolved flux and for $\sim 2 \%$ of the total flux. Estimation of the net fluxes indicated that arsenic was mainly exported (at $\sim 70 \%$ ) as dissolved forms. The relative importance of As(III) in the dissolved and total fluxes was $\sim 15 \%$ and $\sim 10 \%$, respectively. It was thus greater than that reported for fluvial inputs. At this stage, it is worth noting, however, that our estimations are reliable only for the sampled conditions (neap tide, low tide). One can expect substantial differences not only in spring tide conditions but also over the tidal cycle.

\section{Conclusion}

In summary, the behaviour of inorganic arsenic species in the Penzé estuary is controlled by two processes that compete with each other. The co-precipitation of the metalloid with iron oxides in the salinity range $0-10$ induces a removal of $\mathrm{As}(\mathrm{V})$ and $\mathrm{As}(\mathrm{III})$ species whereas diagenetic phenomena, which are the most probable to explain addition of dissolved As, contribute to the release of both inorganic species to the water column. Estimations of As fluxes between the different compartments of the system illustrate the strong reactivity of this element; exchanges between the water column and sediment/particles being on the same order of magnitude as fluvial or net fluxes. Because addition dominates over removal, arsenic, which is mainly imported in particular form ( $\sim 75 \%$ ), is predominantly exported to the coastal area as dissolved species ( $\sim 70 \%)$; As(III), the most toxic species, represents approximately $15 \%$ of the dissolved flux. Such a domination of benthic inputs vs removal and thus elevated As fluxes to the coastal area should be a common feature of the macrotidal systems. In these 
systems, surficial mixing of the sediment is able to overcome the redox barrier and thus to reintroduce the metalloid as dissolved compounds in substantial amounts. However, this assumption needs to be confirmed in other systems; in particular, in estuaries that are more representative, in term of water discharge, of the global scale. In nontidal/microtidal sytems, one can expect, on the contrary, that arsenic is rather trapped into the particulate phase, but this needs also to be further investigated.

\section{References}

Andreae, M.O., 1979. Arsenic speciation in seawater and interstitial waters: the influence of biological-chemical interactions on the chemistry of a trace element. Limnology and Oceanography 24, 440-452.

Andreae, M.O., Andreae, T.W., 1989. Dissolved arsenic species in the Schelde estuary and watershed, Belgium. Estuarine, Coastal and Shelf Science 29, 421-433.

Andreae, M.O., Byrd, J.T., Froehlich, P.N., 1983. Arsenic, antimony, germanium, and tin in the Tejo estuary, Portugal: modeling a polluted estuary. Environmental Science and Technology 17, 731-737.

Andrieux-Loyer, F., Philippon, X., Bally, G., Kerouel, R., Youenou, A., Le Grand, J. 2008. Phosphorous dynamics and bioavailability in sediments of the Penzé Estuary (NW France) in relation to annual P-fluxes and occurrences of Alexandrium minutum. Biogeochemistry 88, 213-231.

Anninou, P., Cave, R.R., 2009. How conservative is arsenic in coastal marine environments? A study in Irish coastal waters. Estuarine, Coastal and Shelf Science $82,515-524$.

Austin, L.S., Millward, G.E., 1986. Atmosphere-coastal ocean fluxes of particulate arsenic and antimony. Continental Shelf Research 6, 459-474.

Boyle, E., Collier, R., Dengler, A.T., Edmond, J.M., Ng, A.C., Stallard, R.F., 1974. On the chemical mass-balance in estuaries. Geochimica et Cosmochimica Acta 38, 1719-1728.

Brenon, I., Le Hir, P., 1999. Modelling the turbidity maximum in the Seine Estuary (France): identification of formation processes. Estuarine, Coastal and Shelf Science 49, 525-544.

Byrd, J.T., Lee, D.S., Smith, R.G., Windom, H.L., 1990. The behavior of trace-metals in the Geum estuary, Korea. Estuaries 13, 8-13.

Cabon, J.Y., Cabon, N., 2000. Determination of arsenic species in seawater by flow injection hydride generation in situ collection followed by graphite furnace atomic absorption spectrometry: stability of As(III). Analytica Chimica Acta 418 $19-31$.

Chilvers, D.C., Peterson, P.J., 1987. Global cycling of arsenic. In: Hutchinson, T.C. Meema, K.M. (Eds.), Lead, Mercury, Cadmium and Arsenic in the Environment Scientific Committee on Problems of the Environment (SCOPE), vol. 31. John Wiley \& Sons, New York.

Cullen, W.R., Reimer, K.J., 1989. Arsenic speciation in the environment. Chemical Reviews 89, 713-764.

Cutter, G.A., Cutter, L.S., Featherstone, A.M., Lohrenz, S.E., 2001. Antimony and arsenic biogeochemistry in the western Atlantic Ocean. Deep Sea Research II 48 2895-2915.

Dabrin, A., Schafer, J., Blanc, G., Strady, E., Masson, M., Bossy, C., et al., 2009 Improving estuarine net flux estimates for dissolved cadmium export at the annual timescale: application to the Gironde Estuary. Estuarine, Coastal and Shelf Science 84, 429-439.

De Gieter, M., Elskens, M., Baeyens, W., 2005. Fluxes and major transport routes of arsenic in the Scheldt estuary. Marine Chemistry 95, 15-30.

Duce, R.A., Liss, P.S., 1991. The atmospheric input of trace species to the world ocean. Global Biogeochemical Cycles 5, 193-259.

Edenborn, H.M., Belzile, N., Mucci, A., Lebel, J., Silverberg, N., 1986. Observation on the diagenetic behavior of arsenic in a deep coastal sediment. Biogeochemistry 2, 359-376.

Elbaz-Poulichet, F., Dupuy, C., Cruzado, A., Velasquez, Z., Achterberg, E.P. Braungardt, C.B., 2000. Influence of sorption processes by iron oxides and algae fixation on arsenic and phosphate cycle in an acidic estuary (Tinto river, Spain). Water Research 34, 3222-3230.

Featherstone A., 1999. Arsenic Speciation in Estuarine and Oceanic Waters by Hydride Generation-Atomic Fluorescence Spectroscopy. PhD thesis, School of Chemistry, University of Tasmania, Hobart, Australia, 225 pp.

Featherstone, A., Butler, E., O'Grady, B., 2004. Seasonal cycling of arsenic species in a stratified, microtidal estuary (Huon River, Tasmania). Estuaries 27, 18-35.

Froelich, P.N., Kaul, L.W., Byrd, J.T., Andreae, M.O., Roe, K.K., 1985. Arsenic, barium, germanium, tin, dimethylsulfide and nutrient biogeochemistry in Charlotte Harbor, Florida, a phosphorus-enriched estuary. Estuarine, Coastal and Shelf Science 20, 239-264.

Howard, A.G., Apte, S.C., Comber, S.D.W., Morris, R.J., 1988. Biogeochemical control of the summer distribution and speciation of arsenic in the Tamar estuary. Estuarine, Coastal and Shelf Science 27, 427-443.

Howard, A.G., Arbab-Zavar, M.H., Apte, S., 1984. The behaviour of dissolved arsenic in the estuary of the River Beaulieu. Estuarine, Coastal and Shelf Science 19, 493-504.

Hunt, L.E., Howard, A.G., 1994. Arsenic speciation and distribution in the Carnon estuary following the acute discharge of contaminated water from a disused mine. Marine Pollution Bulletin 28, 33-38.
Jay, D.A., Musiak, J.D., 1994. Particle trapping in estuarine tidals flows. Journal of Geophysical Research 99 (20), 445-461.

Kitts, H.J., Millward, G.E., Morris, A.W., Ebdon, L., 1994. Arsenic biogeochemistry in the Humber estuary, U.K. Estuarine, Coastal and Shelf Science 39, 157-172.

Knox, S., Langston, W.J., Whitfield, M., Turner, D.R., Liddicoat, M.I., 1984. Statistical analysis of estuarine profiles: II application to arsenic in the Tamar estuary (S.W. England). Estuarine, Coastal and Shelf Science 18, 623-638.

Krom, M.D., Berner, R.A., 1986. The diagenesis of phosphorus in a nearshore marine sediment. Geochimica et Cosmochimica Acta 45, 207-216.

Langston, W., 1983. The behavior of arsenic in selected United Kingdom estuaries. Canadian Journal of Fisheries and Aquatic Sciences 40, 143-150.

Lerat, Y., 1990. Cycles annuels de la matière organique et des éléments nutritifs dans les sédiments d'un écosystème côtier (Baie de Morlaix, France), interactions avec le compartiment pélagique. Faculté des Sciences et Techniques. Université de Bretagne Occidentale, Brest, p. 212.

Lorenzen, C.J., 1967. Determination of chlorophyll and phaeopigments: spectrophotometric equations. Limnology and Oceanography 12, 343-346.

Maher, W., Butler, E.C.V., 1988. Arsenic in the marine environment. Applied Organometallic Chemistry 2, 191-214.

Matschullat, J., 2000. Arsenic in the geosphere - a review. Science of the Total Environment 249, 297-312.

Martin, J.M., Guan, D.M., Elbaz-Poulichet, F., Thomas, A.J., Gordeev, V.V., 1993. Preliminary assessment of the distributions of some trace elements (As, $\mathrm{Cd}, \mathrm{Cu}$, $\mathrm{Fe}, \mathrm{Ni}, \mathrm{Pb}$ and $\mathrm{Zn}$ ) in a pristine aquatic environment: the Lena River estuary (Russia). Marine Chemistry 43, 185-199.

Masson, M., Schafer, J., Blanc, G., Dabrin, A., Castelle, S., Lavaux, G., 2009. Behavior of arsenic and antimony in the surface freshwater reaches of a highly turbid estuary, the Gironde Estuary, France. Applied Geochemistry 24, 1747-1756.

Michel, P., Averty, B., Chiffoleau, J.F., Romana, L.A., Lafite, R., Billen, G., et al., 2001. Biogeochemical behavior of arsenic species in the Seine Estuary in relation to successive high-amplitude primary production, anoxia, turbidity, and salinity events. The Seine estuary: a man-altered macrotidal system. Estuaries 24, 1066-1073.

Michel, P., Boutier, B., Chiffoleau, J.F., 2000. Net fluxes of dissolved arsenic, cadmium, copper, zinc, nitrogen and phosphorus from the Gironde Estuary (France): seasonal variations and trends. Estuarine, Coastal and Shelf Science 51, 451-462.

Michel, P., Chiffoleau, J.F., Averty, B., Auger, D., Chartier, E., 1999. High resolution profiles for arsenic in the Seine estuary. Seasonal variations and net fluxes to the English Channel. Continental Shelf Research 19, 2041-2061.

Mucci, A., Richard, L.F., Lucotte, M., Guignard, C., 2000. The differential geochemical behavior of arsenic and phosphorus in the water column and sediments of the Saguenay Fjord estuary, Canada. Aquatic Geochemistry 6, 293-324.

Murphy, J., Riley, J.P., 1962. A modified single solution method for the determination of phosphate in natural waters. Analytica Chimica Acta 27, 31-36.

Peterson, M.L., Carpenter, R., 1986. Arsenic distribution on porewaters and sediments of puget sound, Lake Washington, the Washington coast and Saanich inlet, B.C. Geochimica et Cosmochimica Acta 50, 353-369.

Quentel, F., Filella, M., Elleouet, C., Madec, C.L., 2006. Sb (III) oxidation by iodate in seawater: a cautionary tale. Science of the Total Environment 355, 259-263.

Riedel, G.F., Sanders, J.G., Osman, R.W., 1987. The effect of biological and physica disturbances on the transport of arsenic from contaminated estuarine sediments. Estuarine, Coastal and Shelf Science 25, 693-706.

Riedel, G.F., Sanders, J.G., Osman, R.W., 1989. The role of three species of benthic invertebrates in the transport of arsenic from contaminated estuarine sediment. Journal of Experimental Marine Biology and Ecology 134, 143-155.

Riso, R.D., Waeles, M., Pernet-Coudrier, B., Le Corre, P., 2006. Determination of dissolved iron(III) in estuarine and coastal waters by adsorptive stripping chronopotentiometry (SCP). Analytical and Bioanalytical Chemistry 385 76-82.

Sanchez-Rodas, D., Gomez-Ariza, J.L., Giraldez, I., Velasco, A., Morales, E., 2005. Arsenic speciation in river and estuarine waters from southwest Spain. Science of the Total Environment 345, 207-217.

Seyler, P., Martin, J.-M., 1990. Distribution of arsenite and total dissolved arsenic in major French estuaries; dependence on biogeochemical processes and anthropogenic inputs. Marine Chemistry 29, 277-294.

Seyler, P., Martin, J.-M., 1991. Arsenic and selenium in a pristine river-estuarine system: the Krka (Yugoslavia). Marine Chemistry 34, 137-151.

Smedley, P.L., Kinniburgh, D.G., 2002. A review of the source, behaviour and distribution of arsenic in natural waters. Applied Geochemistry 17, 517-568.

Sun, Y.-C., Mierzwa, J., Yang, M.-H., 1997. New method of gold-film electrode preparation for anodic stripping voltammetric determination of arsenic (III and V) in seawater. Talanta 44, 1379-1387.

Van der Sloot, H.A., Hoede, D., Wijkstra, J., Duinker, J.C., Nolting, R.F., 1985. Anionic species of V, As, Se, Mo, Sb, Te and W in the Scheldt and Rhine estuaries and the Southern Bight (North Sea). Estuarine, Coastal and Shelf Science 21, 633-651.

Vandenhecke, J., Waeles, M., Riso, R.D., Le Corre, P., 2007. A stripping chronopotentiometric (SCP) method with a gold film electrode for determining inorganic arsenic species in seawater. Analytical and Bioanalytical Chemistry $388,929-937$

Verney, R., Bassoullet, P., Le Hir, P., Jestin, H., Sourisseau, M. Hydrodynamics in a Small Muddy Macrotidal Estuary (Penzé Estuary, NW France): From Monitoring to Modeling PECS 2008: Physics of Estuaries and Coastal Seas, Liverpool, England (UK), 25-29th August. 
Waeles, M., Riso, R.D., Le Corre, P., 2005a. Seasonal variations of cadmium speciation in the Penzé estuary, NW France. Estuarine, Coastal and Shelf Science 65, 143-152.

Waeles, M., Riso, R.D., Le Corre, P., 2005b. Seasonal variations of dissolved and particulate copper species in estuarine waters. Estuarine, Coastal and Shelf Science 62, 313-323.
Waeles, M., Riso, R.D., Le Corre, P., 2007. Distribution and seasonal changes of lead in an estuarine system affected by agricultural practices: the Penzé estuary, NW France. Estuarine, Coastal and Shelf Science 74, 570-578.

Yao, Q.Z., Zhang, J., Qin, X.G., Xiong, H., Dong, L.X., 2006. The behavior of selenium and arsenic in the Zhujiang (Pearl River) estuary, South China Sea. Estuarine Coastal and Shelf Science 67, 170-180. 